\title{
INFANTILE FIBROMATOSIS OF THE SCROTUM: A CASE REPORT
}

\author{
Vivek Patre ${ }^{1}$, Sanjay Thulkar², Immaneni Satish Rao ${ }^{3}$
}

\section{HOW TO CITE THIS ARTICLE:}

Vivek Patre, Sanjay Thulkar, Immaneni Satish Rao. "Infantile fibromatosis of the scrotum: a case report". Journal of Evolution of Medical and Dental Sciences 2013; Vol. 2, Issue 50, December 16; Page: 9657-9660.

ABSTRACT: Infantile fibromatosis is a process that is difficult to differentiate from fibrosarcoma. It is common in neonates and infants and usually arises from head and neck. Only rarely it has been reported to involve the external genitalia or scrotum. We report a case of an eight-month old infant who presented with a painless scrotal mass that has been slowly enlarging for the previous 3months. Gray-scale sonography demonstrated a heterogeneously echogenic paratesticular mass in right hemiscrotum. Histologic examination of the excised mass revealed infantile fibromatosis of the scrotum. Sonographic appearance of this entity has not been described previously.

KEY WORDS: Scrotum; sonography; fibromatosis

INTRODUCTION: Fibromatosis is well known group of tumours in neonates and infants, and rarely it may occur in adult. The process is generally local occurring most frequently in head and neck or extremities [1]. However, it can be a devastating infiltrative multifocal process with visceral involvement [2,3]. We report the unusual case of an eight-month infant with a fibromatosis involving the scrotum.

CASE REPORT: An eight months old male infant was presented to the pediatric surgeon with right scrotal mass that has been slowly enlarging in size since past three months. Scrotal examination revealed a soft to firm non-tender mass in right hemiscrotum. No signs of inflammation were seen. Both testes could not be felt separately from the scrotal mass. There was no other abnormal physical finding. Routine haemogram and chest radiograph was normal.

Sonography was performed with sonoline versa (Siemens, Germany) ultrasound unit using 7.5 MHz linear array transducer. Gray-scale sonography demonstrated an ill marginated, heterogenous, solid soft tissue mass in right scrotal sac. It was seen extending upto scrotal neck, however inguinal canal was normal. It measured about six centimeters in cranio-caudal direction. Internal architecture of the mass demonstrated multiple incomplete hyperechoic bands embedded in the matrix of hypoechoic solid soft tissue (fig. 1, a and b). No associated calcification or cystic changes were demonstrated in the mass.

No detectable vascularity was seen on colour doppler. Right testis is compressed by the mass but it was normal in echotexure (fig. 1, c). Right epididymis was not demonstrated and no free fluid was seen. Left hemiscrotum was normal. Sonographic opinion of right paratesticular tumour was offered but no specific diagnosis could be made. Sonographic examination of abdomen and pelvis was normal. Surgical exploration of the scrotum followed and the mass was excised with blunt dissection. The dissection difficult however, it could be excised completely. Right testis and epididymis were found normal and viable and were left in the scrotum. Gross examination of the surgical specimen demonstrated a well-demarcated, nonencapsulated mass that was composed of a yellow, gelatinous material. It was coarsely trabeculated, which may partially explain it sonographic appearance. No necrosis or cystic changes were grossly apparent. 
Histopathologic examination revealed that the mass was primarily composed of bland spindle cells in a collagenous background. (fig 2a) entrapping the blood vessels and the dartos muscle. The spindle cells did not show any mitosis or atypia and the immunohistochemistry for smooth muscle actin (SMA) and S-100 was negative (Fig. 2b). No inflammatory cells were seen. Thus the final pathological diagnosis was infantile fibromatosis. Postoperative course was uneventful.

DISCUSSION: Sonography is the primary imaging modality when intra scrotal mass is identified and intra- or paratesticular origin of the mass is difficult to assess clinically. It is performed to differentiate testicular from paratesticular lesions, to confirm a tumour by demonstration of a solid mass and to exclude the cystic lesion. ${ }^{[3]}$ However, sonographic appearances are usually nonspecific and it is difficult to differentiate between various tumour types.

Both benign and malignant tumours of the epididymis, spermatic cord, and paratesticular tissues are relatively rare and are primarily seen in older patients. ${ }^{[3]}$ Benign paratesticular tumours include adenomatoid tumour, papillary cystadenoma, fibroma, lymphangioma, adrenal rest tumours and dermoid cysts. Fibroma or fibrous pseudotumour and lipoma of the spermatic cord are important paratesticular benign tumours in children.[4]

Rhabdomyosarcoma is the most important consideration in case of paratesticular tumour occurring in childhood. Other paratesticular malignant tumours such as leiomyosarcoma, liposarcoma, fibrosarcoma and malignant fibrous histiosarcoma are uncommon in children and predominantly occur in men more than 40 years of age.[3] Rhabdomyosarcomas are usually seen in unilateral echogenic masses.[5] The majority of these lesions are separate from testis however, delineation from epididymis may be difficult.[3]

Proliferative disorders of connective tissue can be divided into three groups, fibromas, fibrosarcoma and fibromatosis.[6] Fibromas, also known as fibrous pseudotumour, benign wellcircumscribed tumours and consist of fibro-collagenous tissue on histopathology. These are considered as a benign fibro-inflammatory reaction, rather than a true neoplasm.[4,5,7] Fibrosarcoma are malignant neoplasm of fibroblasts. These are markedly cellular with numerous mitoses and metastasize readily.

Fibromatosis is a term coined by stout to identify a group of connective tissue disorders in which benign versus malignant differentiation is difficult on histopathology.[8,9] These represent connective tissue hyperplasia which are frequently seen at birth or during infancy, although some occur during adult life. These tumors are single or multicentric, circumscribed but not encapsulated, and usually arise from fascia. Proliferation of fibroblasts may be quite intense and the process may invade adjacent structures thus suggesting a fibrosarcoma. However, on histopathology these can usually be differentiated from fibrosarcoma on the basis of degree of cellularity, number of mitoses, and atypical features. It is the generally agreed that fibromatosis do not metastasize but locally aggressive and frequently reoccur if not removed completely.[2]

Congenital fibromatosis is the second most common tumor as a group in the neonatal period. ${ }^{[8]}$ These tumors are solitary and circumscribed, multiple or diffusely infiltrative. The solitary fibromatosis is the most common type, with half of them arising from the head neck. Although circumscribed, they have infiltrative margins and incomplete removal is common. Multiple fibromatosis differs only in the distribution of the tumors. Generalized fibromatosis with visceral 
involvement has been virtually uniformly fatal.[2,8]The process occurs at multiple sites with involvement of bone, liver, gut, heart or lung.

There are few case reports of infantile fibromatosis involving the scrotum and sonographic appearance of this entity has not been described previously.

\section{REFERENENCES:}

1. Kauffman SL and Stout A P. Congenital mesenchymal tumors. Cancer 1965;18: 460-476.

2. Brock J W-III and Jones C. Infantile fibromatosis of the external genitalia: diagnosis and management strategy. J.Urol. 1993; 149(2):375-358.

3. Sailkar MG, Yuvraja TB, Ramadwar MR, Kurkure PA, Tongaonkar HB. Infantile fibromatosis of scrotum. Ind J Sur 2005; 67: 273-275.

4. Hricak $H$. The epididymis, spermatic cord, and paratesticular tissue: congenital anomalies and tumours. In: Hricak H, Hamm B, Kim B, editors. Imaging of the scrotum : textbook and atlas. New York: Raven press; 1995. P 129.

5. Skoog SJ. Benign and malignant pediatric scrotal masses. Pediatr Clin North Am 1997; 44: 1229.

6. Fleischmajer R, Nedwich A. and Reeves J RT. Juvenile fibromatosis. Arch Dermatol 1973;107: 574-579.

7. Jones Ma, Yong RH, Scully RE. Benign fibromatous tumours of the testis and paratesticular region a report of 9 cases with a proposed classification of fibromatous tumours and tumour like lesion. Am J Surg Path 1997; 21: 296.

8. Woodward PJ, Schwab CM, Sesterhen IA. Extratesticular scrotal masses: radiologic pathologic correlation. Radiographics 2003; 23: 215.

9. Stout A P. Juvenile fibromatosis. Cancer 1954; 7: 953-978.
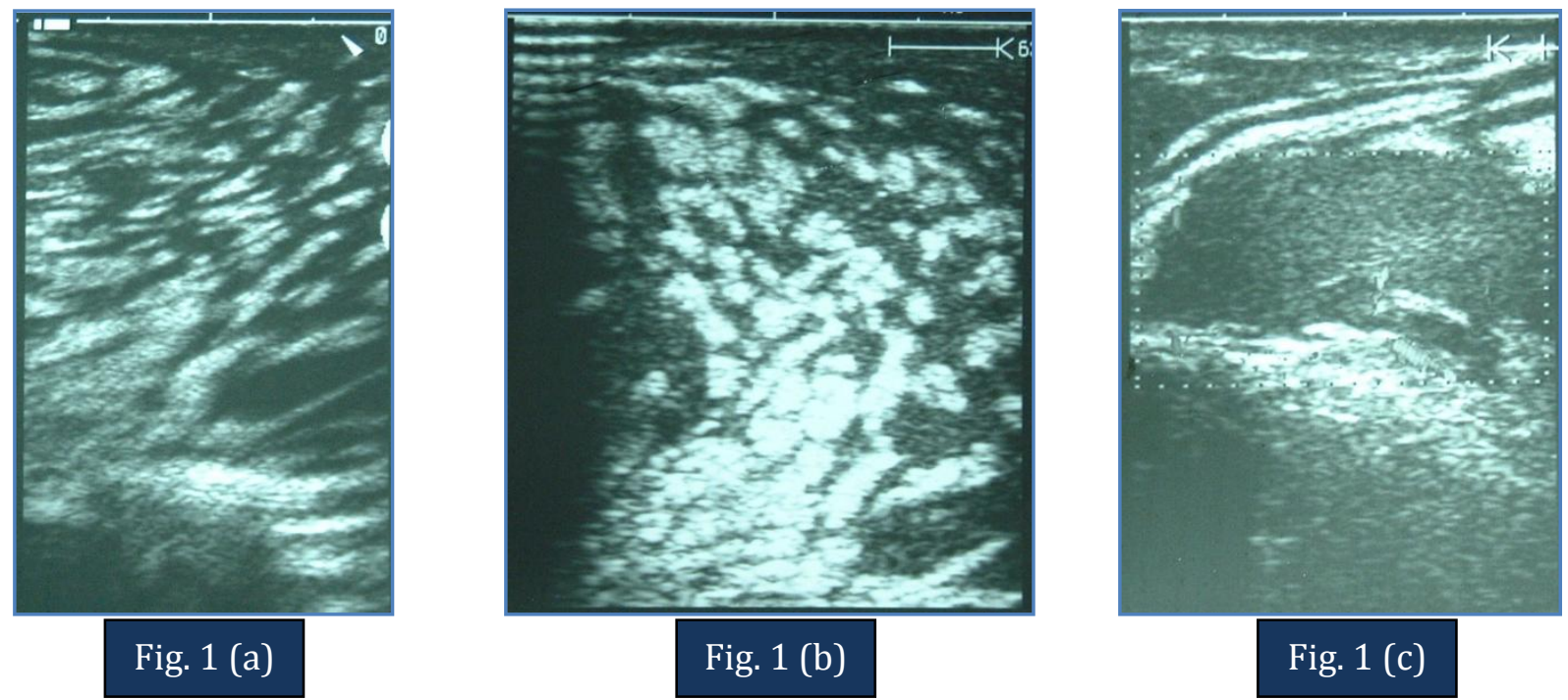

Fig. 1 (a, b, c) Sonogram of right hemiscrotum. Longitudinal (a) and transverse (b) scan shows poorly defined intrascortal mass with heterogenous echotexure. Linear, band like hyperechoic areas are seen within moderately echogenic matrix. Right testis is encased by the mass but appears normal in outline and echotexure (c). 


\section{CASE REPORT}

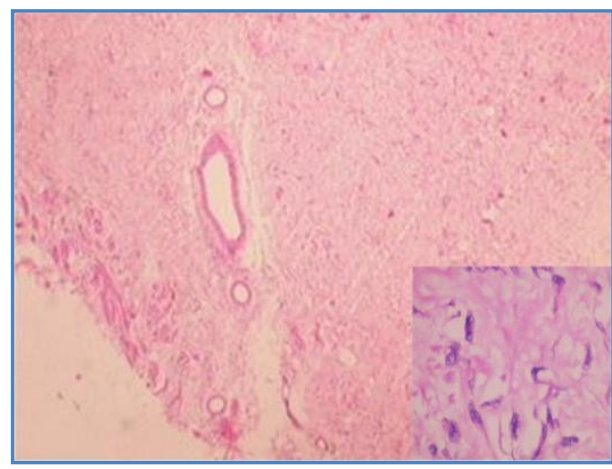

Fig. 2 (a)

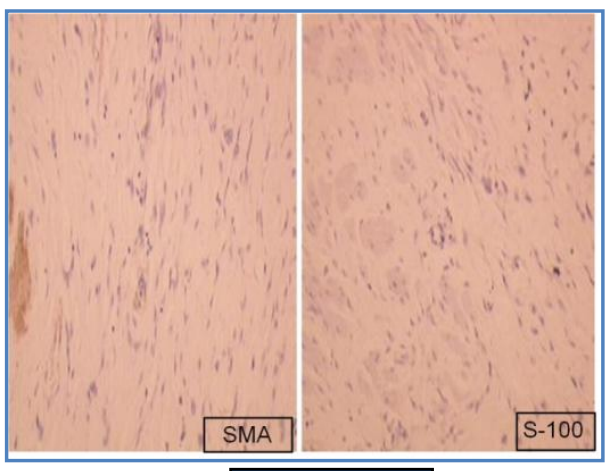

Fig. 2 (b)

Fig. 2 (a, b) Histopathology of excised specimen. (a) The lesion is primarily composed of bland spindle cells which are encasing blood vessels and the dartos muscle. High magnification inset shows spindle cells enmeshed in collagenous stroma. No mitosis or atypia was seen. (b) Immunohistochemistry show that the muscle fibres are highlighted but the spindle cells are nonreactive for smooth muscle actin (SMA) and S-100.

\section{AUTHORS:}

1. Vivek Patre

2. Sanjay Thulkar

3. Immaneni Satish Rao

\section{PARTICULARS OF CONTRIBUTORS:}

1. Senior Resident, Department of Radiodiagnosis, All India Institute of Medical Sciences, New Delhi, India.

2. Additional Professor, Department of Radiodiagnosis, All India Institute of Medical Sciences, New Delhi, India.

3. Senior Resident, Department of Pathology, All India Institute of Medical Sciences, New Delhi, India. 